\title{
Effect of Extraction Solvent on Total Phenol, Flavonoid Content, and Antioxidant Activity of Avicennia Officinalis
}

\author{
Ngoc-Van Thi Nguyen 1,*iD, Ngan Tuyet Duong ${ }^{1}$ (D), Kim-Ngan Huynh Nguyen ${ }^{1}$ (D), \\ Nguyen Thao Bui ${ }^{1}$ (D), To-Lien Thi Pham ${ }^{1}$, Kien Trung Nguyen ${ }^{2}$ (D), Phuoc Huu Le ${ }^{3}$ (D), \\ Kyeong-Ho Kim 4 (iD
}

1 College of Pharmacy, Can Tho University of Medicine and Pharmacy, 179 Nguyen Van Cu Street, Can Tho City, Vietnam; duongngan1404@gmail.com (N.T.D); nhkngan94@gmail.com (K.N.N.H); buithaonguyen2708@gmail.com (N.T.B); pttlien@ctump.edu.vn (T.L.T.P);

2 College of Medicine, Can Tho University of Medicine and Pharmacy, 179 Nguyen Van Cu Street, An Khanh Ward, Ninh Kieu District, Can Tho City, Vietnam; ntkien@ ctump.edu.vn (K.T.N);

3 Department of Physics and Biophysics, Faculty of Sciences, Can Tho University of Medicine and Pharmacy, 179 Nguyen Van Cu, Can Tho 94000, Vietnam; lhuuphuoc@ctump.edu.vn (P.H.L.);

4 College of Pharmacy, Kangwon National University, 1 Gangwondaehak-gil, Hyoja-dong, Chuncheon-si, Gangwon-do, South Korea; kyeong@kangwon.ac.kr (K.H.K);

* Correspondence: nguyenthingocvanct@gmail.com (N.V.T.N);

Scopus Author ID: 55420442800

Received: 15.05.2021; Revised: 14.06.2021; Accepted: 16.06.2021; Published: 24.06.2021

\begin{abstract}
The mangrove plant - Avicennia officinalis L has been widely used for the treatment of various diseases such as anti-inflammatory, anticancer, antioxidant therapy. In this study, we optimize the extraction process using the easily obtainable solvents with different polarities toward obtaining high total phenolic- and flavonoid- contents from Avicennia officinalis L's leaves. The influences of solvents (i.e., methanol, ethanol, ethyl acetate, acetone, dichloromethane, and chloroform) in the extraction process on total phenolic-, flavonoid- contents and their antioxidant activity were investigated. Avicennia officinalis $\mathrm{L}$ was extracted using six solvents. The total phenolic and flavonoid contents were determined by the phytochemical screening method. The antioxidant activity of extracted phenolics and flavonoids was studied by using 2,2-diphenyl-1-picrylhydrazy (DPPH) radical scavenging assay and 2,2-azinobis- (3-ethylbenzothiazoline-6-sulfonate) (ABTS+) radical scavenging assay. As a result, the highest extraction yield was obtained using methanol (10.56\%). In addition, the extract obtained using acetone solvent exhibited the highest antioxidant activity in the DPPH assay. Meanwhile, the extract obtained using ethyl acetate solvent showed the highest antioxidant activity in the ABTS+ assay. The acetone- extract also exhibited high phenolic content (100.64 mg GAE/g) and flavonoid content (95.44 mg QCE/g). This study confirms that, besides commonly used solvents such as methanol, ethanol, etc., acetone is also a good solvent for extracting polyphenols from the mangrove plant - Avicennia officinalis L. for antioxidants.
\end{abstract}

Keywords: Avicennia officinalis; antioxidant activity; phenolics; flavonoids; solvents.

(C) 2021 by the authors. This article is an open-access article distributed under the terms and conditions of the Creative Commons Attribution (CC BY) license (https://creativecommons.org/licenses/by/4.0/).

\section{Introduction}

In recent years, natural antioxidants discovered in plants have attracted significant interest due to their widely acclaimed nutritional and therapeutic values. The antioxidant properties of plant-derived compounds/ extracts are valuable for understanding the biochemical mechanisms of several folk remedies and other medical applications [1,2]. Studies on the bioactivities of various plants have attracted a great deal of attention because the effectiveness 
of the plant extracts can be significantly varied depending on the solvents used in the extraction process $[3,4]$, and the used part, age, geographical origin of plants [5,6]. Several methods are popularly used to extract antioxidant compounds from plants, such as Soxhlet extraction, maceration, supercritical fluid extraction, and ultrasound-assisted extraction [5]. Besides the extraction method, the used solvent is an important factor that can significantly affect the extracts' extraction yield and antioxidant activity [3,4,7]. The antioxidant compounds with different chemical properties and polarities can or cannot be soluble in a specific solvent [8].

Mangroves are salt-tolerant trees and shrubs that grow in muddy and wet soil along the tropical and subtropical coastlines $[9,10]$. Wetlands are among the most productive and diverse ecosystems globally [11], and they can also be thought of as a contaminant reservoir [11]. Mangroves can thrive in ecologically hostile conditions such as high salinity, heavy metals, flooding, UV-B, and waterlogging [12,13]. Thus, mangrove plants are said to be enriched with a unique and diverse class of phytochemicals to survive in these harsh conditions. The presence of the phytochemicals may be responsible for the ethnomedicinal uses of mangrove plants to treat various ailments $[14,15]$. Mangroves are now thought to have nutritional values and medicinal uses owing to their high antioxidant, antiradical scavenging activity, antibacterial and antifungal activity [1,2,13-18]. Mangrove plants may contain phenolic compounds such as phenolic acid, flavonoids, quinones, coumarins, lignans, stilbenes, and tannins as free radical scavenging molecules [1,13,19-21].

Avicennia is the major mangrove genus in the Avicenniaceae family. It is the most prevalent genus in mangrove habitats with eight to ten species documented globally [6]. Avicennia officinalis is a medium-sized mangrove plant that grows in brackish water and is common along the subtropical coast [15,22]. Ethnomedicinal practices also report the use of stem/bark of this plant as a contraceptive, astringent, diuretic, antiulcer, treatment for snake bites, rheumatism, smallpox, skin diseases, hepatitis, leprosy, antitumor, bronchial asthma, antibacterial, gastroprotective, aphrodisiac, boils, abscesses, etc. [12,23,24]. The pharmacological studies have also reported the antimicrobial, antiulcer, anti-inflammatory, anticancer, and antioxidant activities of different leaf and bark extracts of Avicennia officinalis $[12,24-26]$. This plant is an evergreen species of mangrove that is mainly found in Bangladesh, India, Indonesia, Malaysia, Brunei, Myanmar, Vietnam, and southern Papua New Guinea [27].

To the best of our knowledge, the effects of extraction solvents on phenolic- and flavonoid- contents and antioxidant activities of Avicennia officinalis have not been reported, although a similar work on Phoenix dactylifera L. has been reported [4]. In this study, we optimize the extraction process from Avicennia officinalis' leaves using some easily obtainable solvents with different polarities. The influences of the extraction parameters on total phenolic and flavonoid contents and antioxidant activity are also investigated and reported.

\section{Materials and Methods}

\subsection{Materials.}

Folin-Ciocalteu (FC) reagent, sodium carbonate anhydrous, gallic acid, sodium nitrite, sodium hydroxide, aluminum chloride anhydrous, 2,2-diphenyl-1-picrylhydrazyl (DPPH), 2,2'azinobis-3-ethyl benzothiazonline-6-sulfonate (ABTS), trichloroacetic acid, ferric chloride anhydrous, gallic acid, quercetin, and Trolox were purchased from Sigma-Aldrich GmbH (Merck, Germany). 


\subsection{Sample preparation.}

Leaves of fresh Avicennia officinalis $(10 \mathrm{~kg})$ were collected in $\mathrm{Ca}$ Mau province, Mekong Delta, Vietnam. The leaves were washed with water to remove soil and dirt. The moisture of the dried sample was lower than 13\%. All samples were stored in black glass containers and kept at room temperature. The plants were identified by PCR methods at the Department of Biology, Can Tho University, Vietnam.

\subsection{Extraction.}

In this study, the ultrasound-assisted extraction (UAE) method was used to extract phenolics and flavonoids from the leaf of Avicennia officinalis. It is worthy of mentioning that UAE offers several advantages, including high extraction efficiency, good reproducibility, low solvent consumption speed, low cost, environmental friendliness, laboratory availability, and ease of scale-up for industrial applications. The high extraction efficiency of UAE method is attributed to the production and bursting of cavitation bubbles at the surfaces of plant samples, which enhanced solvent penetration into the plant material and mass transfer of the phenolic acids and flavonoids across disrupted cellular membranes into solution [28]. Using this general strategy, the phenolic extraction efficiencies of different parts of Avicennia officinalis can be optimized based on the difference in relative polarity of target compounds. Therefore, different extraction solvents should be chosen depending on the known distribution of target compounds in various plant anatomical locations. In this study, six different solvents (i.e., methanol, ethanol, ethyl acetate, acetone, dichloromethane, and chloroform) in ascending polarity were used to extract the soluble compounds from leaves of Avicennia officinalis. Air-dried-leaf samples ( $20 \mathrm{~g}$ ) were extracted in an ultrasonic bath three times for $90 \mathrm{~min}$ (30 min each time). The extracted solutions were combined in an Erlenmeyer flask. Methanol, ethanol, ethyl acetate, acetone, dichloromethane, and chloroform in the extracts were removed using a rotary evaporator to obtain the extracts. The organic solvent extracts were dissolved in methanol (2 $\mathrm{mg} / \mathrm{ml})$. The extraction yield of samples calculated by using the following formula:

$$
\text { Yield }(\mathrm{g} / 100 \mathrm{~g})=(W 1 \times 100) / W 2
$$

where $W 1$ is the weight of the extract residue obtained after solvent removal, and $W 2$ is the weight of samples taken before extracting.

\subsection{Methods for polyphenol content determination.}

Total phenol content (TPC) in each extract was determined using the Folin-Ciocalteu method described by McDonald et al. [29], with minor modifications. The diluted extract or gallic acid $(250 \mu \mathrm{l})$ will be oxidized with $250 \mu \mathrm{l}$ of Folin-Ciocalteu's reagent and neutralized by adding $250 \mu \mathrm{l}$ of $10 \% \mathrm{Na}_{2} \mathrm{CO}_{3}$. The mixture was allowed to stand for 30 minutes at room temperature. The absorbance at $760 \mathrm{~nm}$ of the mixtures was measured using a UV-VIS spectrophotometer (V-550 model Jasco, Tokyo, Japan). TPC was expressed as milligram gallic acid equivalent per gram defatted Avicennia officinalis (mg GAE/g extract).

The total flavonoid content (TFC) of each extract was investigated using the aluminum chloride colorimetric method described by Chang et al. [30] with slight modifications. The calibration curve was prepared by diluting quercetin in methanol $(10-120 \mathrm{mg} / \mathrm{ml})$. The diluted extract or quercetin $(250 \mu \mathrm{l})$ was mixed with $200 \mu \mathrm{l}$ of distilled water, $200 \mu \mathrm{l}$ of $5 \% \mathrm{NaNO}_{2}$. Then $200 \mu \mathrm{l}$ of $10 \% \mathrm{AlCl}_{3}(\mathrm{w} / \mathrm{v}$ ) was added to the mixture. After 6 minutes, $600 \mu \mathrm{NaOH} 1 \mathrm{M}$ was added and the volume was made up to $1.5 \mathrm{ml}$ with distilled water. The maximum 
absorbance of the mixture was measured at $510 \mathrm{~nm}$ using a UV-VIS spectrophotometer. TFC was expressed as milligram quercetin equivalent per gram defatted Avicennia officinalis (mg QCE/g extract).

\subsection{Methods for studying antioxidant activities.}

2.5.1. DPPH radical scavenging activity.

2,2-Diphenyl-2-picrylhydrazyl (DPPH) radical scavenging capacities of the plant extracts were estimated by reducing the reaction color between DPPH solution and sample extracts, as previously described in refs. [31,32]. The plant extract at various concentrations was diluted with methanol to get a sample solution. One milliliter of each solution was transferred to a test tube and mixed with $200 \mu \mathrm{l}$ of $1000 \mu \mathrm{g} / \mathrm{ml} \mathrm{DPPH}$ volume made up to $2 \mathrm{ml}$ with methanol. Afterward, the reaction solutions were kept in the dark for $30 \mathrm{~min}$ at ambient temperature before measuring their absorbance at $517 \mathrm{~nm}$. In this study, Trolox was used as a standard substance; blanks were run in each assay. DPPH radical ability was expressed as IC50 $(\mathrm{mg} / \mathrm{ml})$, and the inhibition percentage was calculated using the following formula:

$$
\text { DPPH scavenging activity }(\%)=\frac{\left(A_{0-} A_{1}\right)}{A_{0}} \times 100
$$

where $A_{0}$ is the absorbance of the control sample, and $A_{l}$ is the absorbance of a sample. All tests were performed at least in triplicate, and the average of three determinations was used to plot in the graphs.

\subsubsection{ABTS radical scavenging assay.}

In 2,2-azinobis-(3-ethylbenzothiazoline-6-sulphonate) (ABTS) assay, the plant extract will be reacted with $\mathrm{ABTS}^{+}$, and a model stable-free radical derived from $\mathrm{ABTS}^{+}$assay was reported by L.H. Long and B. Halliwell (2001) [33]. The ABTS ${ }^{+}(990 \mu 1)$ was added to the extracts $(10 \mu \mathrm{l})$ in the test tube and shook thoroughly for 10 seconds. The mixture was held at room temperature for 6 min before absorbance was immediately measured at $734 \mathrm{~nm}$. The assay was performed at least in triplicates. The assay was first carried out on Trolox, which served as a standard. ABTS scavenging ability was expressed as $\mathrm{IC}_{50}(\mathrm{mg} / \mathrm{ml})$, and an inhibition percentage was calculated using the following formula:

$$
\text { ABTS scavenging activity }(\%)=\frac{\left(A_{0-} A_{1}\right)}{A_{0}} \times 100
$$

where $A_{0}$ is the absorbance of the control sample, and $A_{l}$ is the absorbance of the sample.

\subsection{Statistical analyses.}

All analyses were done at least in triplicate, and average values and the standard derivations were used to present the data in this study. Data were analyzed using Microsoft Excel 2016. Statistical comparisons were performed with a one-way analysis of variance, and $\mathrm{p}$ values $<0.05$ were regarded as significant. The correlation coefficients $(\mathrm{R})$ between TPC and TFC were calculated to determine their relationship. 


\section{Results}

\subsection{Results of solvent on extraction yield and polyphenol content.}

\subsubsection{Extraction yield.}

Avicennia officinalis extracts were obtained using six different solvents, namely methanol, ethanol, ethyl acetate, acetone, dichloromethane, and chloroform. Extraction yields ranged from $2.17 \%$ for dichloromethane to $10.56 \%$ for methanol (Table 1). The yields of extraction by various solvents decreased in the order: Methanol > Ethanol > Acetone > Chloroform $>$ Ethyl acetate $>$ Dichloromethane. This result indicates that the extraction yield increases with increasing polarity (e.g., methanol, ethanol, acetone). Whereas the yield of a Chloroform extract $(3.20 \%)$ is not the lowest value, although it has the lowest polarity among the solvents.

Table 1. Extraction yield, TPC, TFC of Avicennia officinalis extracts using different solvents.

\begin{tabular}{l|c|c|c}
\multicolumn{1}{c|}{ Solvent } & $\begin{array}{c}\text { Extraction yield } \\
(\boldsymbol{\%})\end{array}$ & $\begin{array}{c}\text { TPC } \\
(\mathbf{m g ~ G A E} / \mathbf{g})^{\mathbf{1}}\end{array}$ & $\begin{array}{c}\text { TFC } \\
(\mathbf{m g ~ Q C E} / \mathbf{g})^{\mathbf{2}}\end{array}$ \\
\hline Methanol & $10.56 \pm 0.66$ & $67.61 \pm 0.03$ & $94.02 \pm 0.05$ \\
\hline Ethanol & $8.95 \pm 0.69$ & $71.82 \pm 0.02$ & $73.55 \pm 0.02$ \\
\hline Ethyl acetate & $2.45 \pm 0.06$ & $108.16 \pm 0.03$ & $88.22 \pm 0.07$ \\
\hline Acetone & $3.35 \pm 0.06$ & $100.64 \pm 0.03$ & $95.44 \pm 0.04$ \\
\hline Dichloromethane & $2.17 \pm 0.01$ & $43.05 \pm 0.01$ & $61.04 \pm 0.02$ \\
\hline Chloroform & $3.20 \pm 0.57$ & $73.48 \pm 0.02$ & $61.40 \pm 0.03$
\end{tabular}

\subsubsection{Total phenolic contents (TPC).}

Table 1 shows TPC of the extracts measured using the FC method. TPC values were obtained from a calibration curve $\mathrm{y}=0.1383 \mathrm{x}-0.0053$ with $\mathrm{R}^{2}=0.9926$, where $\mathrm{x}$ is the absorbance, and $\mathrm{y}$ is the concentration of a gallic acid solution $(\mathrm{mg} / \mathrm{ml})$, expressed as $\mathrm{mg}$ GAE/g extract. The TPC values of the extracts range from $43.05 \mathrm{mgGAE} / \mathrm{g}$ for dichloromethane to $108.16 \mathrm{mg} \mathrm{GAE} / \mathrm{g}$ for ethyl acetate (Table 1). The TPC values decrease in the order: Ethyl acetate $>$ Acetone $>$ Chloroform $>$ Ethanol $>$ Methanol $>$ Dichloromethane. The TPC of the ethyl acetate extract is not significantly higher than that of the acetone extract (108.16 vs. $100.64 \mathrm{mg}$ GAE/g). Meanwhile, the TPC of the dichloromethane extract is significantly lower than those of other solvents.

\subsubsection{Total flavonoid contents (TFC).}

Total flavonoid contents were also summarized in Table 1 . TFC values were obtained from a calibration curve $\mathrm{y}=0.0905 \mathrm{x}-0.0027$ with $\mathrm{R}^{2}=0.9977$, where $\mathrm{x}$ is the absorbance, and $\mathrm{y}$ is the concentration of quercetin solution $(\mathrm{mg} / \mathrm{ml})$, expressed as $\mathrm{mg}$ QCE/g extract. The TFC values of the extracts varied from $61.04 \mathrm{mg}$ QCE/g for dichloromethane to $95.44 \mathrm{mg}$ QCE/g for ethyl acetate (Table 1), and they decrease in the order: Acetone > Methanol > Ethyl acetate $>$ Ethanol $>$ Chloroform $>$ Dichloromethane. The TFC of the acetone extract is considerably higher than those of other extracts. 


\subsection{Results of solvent on the antioxidant assay.}

The effects of Avicennia officinalis extraction solvents (i.e., methanol, ethanol, ethyl acetate, acetone, dichloromethane, and chloroform) on DPPH radical scavenging activity are shown in Figure 1. Obviously, the percentage of scavenging effect on the DPPH radical was increased monotonically with increasing the concentration of Avicennia officinalis extracts from 50 to $350 \mu \mathrm{g} / \mathrm{ml}$. At a $350 \mu \mathrm{g} / \mathrm{ml}$ concentration, the DPPH radical scavenging activity of acetone- and methanol- extracts were $77.16 \%$ and $75.75 \%$, respectively. Among the investigated extracts, Avicennia officinalis extracts using acetone exhibited maximum DPPH radical scavenging activity. However, the antioxidant activity of all the extracts significantly lower than the Trolox standard. Particularly, the IC50 value of Trolox was $7.39 \mu \mathrm{g} / \mathrm{ml}$, while the IC50 value of acetone extract was $155.68 \mu \mathrm{g} / \mathrm{ml}$ (Table 2).

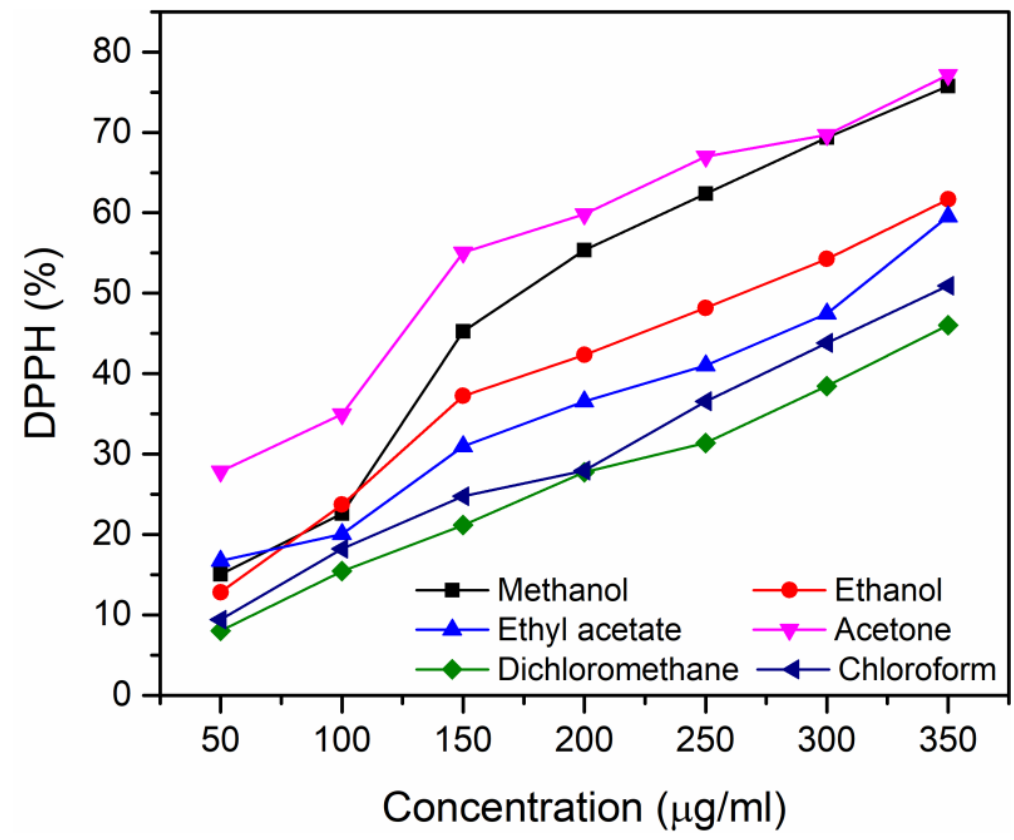

Figure 1. DPPH radical scavenging activity of Avicennia officinalis extracted using different solvents.

Table 2. Effect of A. officinalis leaf extract on DPPH and ABTS radical scavenging activities

\begin{tabular}{l|c|c}
$\begin{array}{l}\text { Extraction solvents and } \\
\text { standard substance }\end{array}$ & $\begin{array}{c}\text { DPPH } \\
\left(\text { IC }_{\mathbf{5 0}}\right)\end{array}$ & $\begin{array}{c}\text { ABTS } \\
\text { (IC50) }\end{array}$ \\
\hline Methanol & $194.31 \pm 2.99$ & $37.92 \pm 2.11$ \\
\hline Ethanol & $257.04 \pm 3.30$ & $42.73 \pm 0.86$ \\
\hline Ethyl acetate & $287.53 \pm 2.15$ & $31.90 \pm 2.61$ \\
\hline Acetone & $155.68 \pm 2.96$ & $40.43 \pm 3.69$ \\
\hline Dichloromethane & $396.05 \pm 3.38$ & $53.92 \pm 2.45$ \\
\hline Chlorofom & $348.0 \pm 1.4$ & $41.76 \pm 3.28$ \\
\hline Trolox & $7.39 \pm 0.38$ & $0.63 \pm 0.01$
\end{tabular}

The effects of Avicennia officinalis extraction solvents on $\mathrm{ABTS}^{+}$radical cation are presented in Figure 2. The scavenging effect increases when the sample concentration increases from 10 to $100 \mu \mathrm{g} / \mathrm{ml}$. At $100 \mu \mathrm{g} / \mathrm{ml}$, the scavenging activity on $\mathrm{ABTS}^{+}$of methanol and ethyl acetate extracts achieved high values of $93.41 \%$ and $92.18 \%$, respectively. At $100 \mu \mathrm{g} / \mathrm{ml}$ concentration, the $\mathrm{ABTS}^{+}$activity of extraction solvents researched was higher than $80 \%$. The IC 50 value of Trolox was $0.63 \mu \mathrm{g} / \mathrm{ml}$, and ethyl acetate extract was found to be $31.90 \mu \mathrm{g} / \mathrm{ml}$ (Table 2). The plant extracts' scavenging activity of ABTS+ radical was found to be 
appreciable; this implies that the plant extract may be useful for treating radical-related pathological damage, especially at higher concentrations [34].

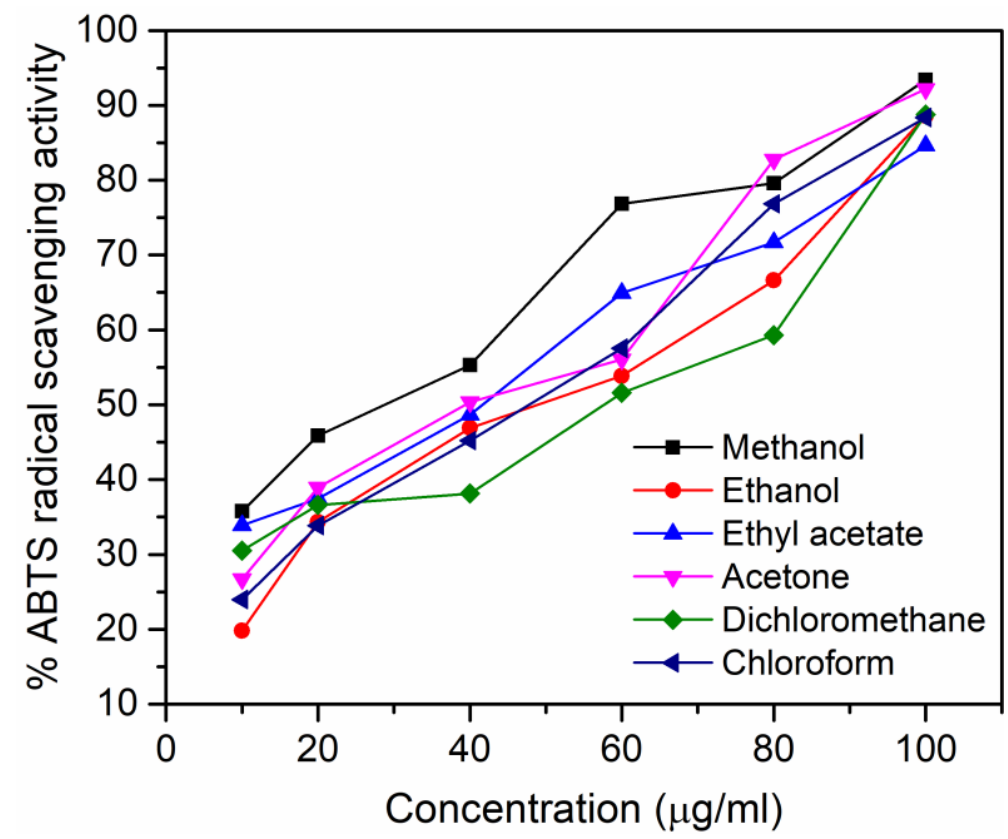

Figure 2. $\mathrm{ABTS}^{+}$radical scavenging activity of Avicennia officinalis extracted using different solvents.

\section{Discussion}

\subsection{Effects of solvent on extraction yield and polyphenol content.}

\subsubsection{Extraction yield.}

Milling, grinding, homogenization, and extraction are the steps for extracting phytochemicals from plants. Since the concentration of biologically active compounds in natural plants is very low, optimization of extraction method using suitable solvents is a critical step in discovering process and isolating phytochemicals from plant materials. Generally, the chemical nature of phytochemicals, extraction method, sample particle size, solvent, and the presence of interfering substances have an impact on the extraction efficiency [28]. For choosing the right extraction solvents, a wide range of polarity solvents should be studied.

The extraction yield in the present study increased with increasing polarity (e.g., methanol, ethanol, acetone). Extraction using ethanol solvent resulted in a relatively high yield (8.953\%), which was comparable to the ethanol extract yield of $8.94 \%$ by using a shaker from Moringa oleifera leaves. The present extract yield is higher than the ethanol- extract yields of $8 \%$ and 5.2\% for Avicennia officinalis leaves in refs. [23,35]. L. Sulmartiwi et al. [36] reported extract yields of Avicennia rumphiana leaves in Indonesia using ethanol solvent (6.24\%) and ethyl acetate solvent (1.38\%). The reasons for the extraction yield difference could be a variance of soil between countries, chemical compounds in different species of Avicennia genus, and the extraction method of each study.

Most researches on Avicennia officinalis usually use ethanol solvent for extracting $[23,27]$. In this study, the highest yield was obtained for methanol. It is suggested that phenolics should be greatly extracted and thus contribute to the higher yield of the methanol- extract. This may be attributable to the higher solubility of proteins and carbohydrates in methanol than that in ethanol and acetone [37]. The results of this study are consistent with the extraction yields of Aegiceras corniculatum- a mangrove plant [38] and some other medicinal plants [39]. 


\subsubsection{Total phenolic contents.}

Table 1 summarizes the content of phenolic compounds (mg GAE/g extract) in different solvent extracts from the leaves Avicennia officinalis. The total phenolic content (TPC) in the different solvent extracts ranges between 43.05 and $108.16 \mathrm{mg}$ GAE/g extract. The highest TPC (108.16 mg GAE/g extract) was achieved for ethyl acetate, followed by TPC of 100.64 $\mathrm{mg} \mathrm{GAE/g} \mathrm{extract} \mathrm{for} \mathrm{acetone.}$

In general, the extractability of a specific component depends on the extraction polarity and the solute-to-solvent ratio. Furthermore, the recovery of phenolic compounds appears to depend on the extraction solvents, their polarity index (PI), and the solubility of phenolic compounds in the extraction solvents. Polyphenol solubility was primarily determined by the presence and position of hydroxyl groups and the molecular size and length of constituent hydrocarbon chains. Phenolic compounds are frequently extracted in greater quantities in high polar solvents [40]. However, we found that methanol (PI =6.6) resulted in lower efficiency in extracting polyphenolic compounds than ethyl acetate $(\mathrm{PI}=4.4)$ and acetone $(\mathrm{PI}=5.1)$.

In the same plant, different parts may synthesize and store different chemicals or varying quantities of a particular compound as a result of their varying gene expression, which affects antioxidant activities and other biological properties of the plant extracts [41,42]. The present TPC results are higher than the results reported by Febriani et al. [42], in which the reported TPC values of Avicennia marina - ethanol extracts were $23.024 \mathrm{mg}$ GAE/g for leaves, $49.119 \mathrm{mg} \mathrm{GAE} / \mathrm{g}$ for fruits, and $33.738 \mathrm{mg} \mathrm{GAE} / \mathrm{g}$ for stem barks. In addition, TPC of Avicennia rumphiana extracts was $1.436 \mathrm{mg}$ GAE/g for ethyl acetate extract from leaves, $1.2431 \mathrm{mg} \mathrm{GAE} / \mathrm{g}$ for ethyl acetate extract from bark $0.8761 \mathrm{mg}$ GAE$/ \mathrm{g}$ for ethanol extract from leaves [36]. Similar to our results, methanol and ethanol have been recognized as effective solvents for extracting phenolic compounds [3]. Meanwhile, acetone, methanol, and water were relatively ineffective for the phenolic extraction from grape seeds [43].

The polarity of the extraction solvents and the solubility of each component in the solvents impact the recovery of phenolic contents in various samples $[4,44]$. Therefore, it is difficult to select a completely appropriate solvent for phenolic extraction from multiple plants. The yield of polyphenol content and the antioxidant activity of extracts can be higher in high polarity solvents, and this guides us in selecting good solvents for screening of multi-sample substances. In light of these observations, it should be mentioned that phenolic compounds are frequently associated with other biomolecules (e.g., polysaccharides, proteins, terpenes, chlorophyll compounds). Consequently, a suitable solvent for a specific compound extraction must be used based on the specific target molecule's structural features and related level of aqueous solubility [45].

\subsubsection{Total flavonoid contents (TFC).}

TFC of the extracts was determined using colorimetric methods. The flavonol/flavone content of various plant extracts was determined using quercetin equivalent as a reference $[1,38]$. We consider the major features of target compounds to gain insight into the molecular mechanism that can affect solvent extraction efficiency. For example, the aluminum chloride method involves forming stable acid complexes between the $\mathrm{AlCl}_{3}$ reagent and $\mathrm{C}-4$ keto group, as well as the C-3 or C-5 hydroxyl group of flavones and flavonols. Furthermore, the orthodihydroxyl groups in flavonoids' A- or B-rings complexes with labile acid form aluminum chloride [5]. 
For the present plant materials, the highest flavonoid yields were found in acetone and methanol extract (95.44 mg QCE/g and $94.02 \mathrm{mg}$ QCE/g, respectively), and these values were much higher than the TFC yield of $3.92 \mathrm{mg}$ Quercetin Equivalent (QE)/g dry leaf Avicennia officinalis sample extracted using petroleum ether [46]. It indicates that the extractions using acetone and methanol solvents were superior to the other solvents for the high recovery of total flavonoids from Avicennia officinalis. It means that polyphenols from Avicennia officinalis were extracted most efficiently in the higher polarity solvents.

\subsection{Solvent effects on antioxidant activities.}

\subsubsection{DPPH radical scavenging activity.}

DPPH free radical scavenging assay is a method to assess the antioxidant activity of bioactive compounds. It is an easy-, rapid- and sensitive- method for the antioxidant screening of plant extracts [47]. DPPH is a stable nitrogen-centered organic free radical with an absorption peak at $517 \mathrm{~nm}$. It loses absorption as accepting electrons or free radical species, which is observed by noticeable discoloration from purple to yellow. DPPH can accommodate many samples in a short period and is sensitive enough to detect active ingredients at low concentrations $[12,48]$.

DPPH radical scavenging activity of the various Avicennia officinalis extracts using six different solvents is shown in Figure 1. The obtained extracts exhibited free radical scavenging properties and low $\mathrm{IC}_{50}$ values, which are indicative of robust antioxidant capacities. The $\mathrm{IC}_{50}$ values varied from $31.90 \pm 2.61$ for ethyl acetate to $53.92 \pm 2.45 \mu \mathrm{g} / \mathrm{ml}$ for acetone. Clearly, the acetone extracts exhibited potent scavenging capacity against the free radical DPPH. This acetone extract result was much better than those obtained in $96 \%$ ethanol extract of leaves of Avicennia officinalis $(160.9 \mu \mathrm{g} / \mathrm{ml})$ reported by Khushi et al. [27]. Meanwhile, Masoko and Eloff [49] found strong antioxidant activity in different plants of the family Combretaceae extracted by acetone solvent. Moreover, Sulmartiwi et al. [37] found the lowest IC $_{50}$ value in ethyl acetate extract from Avicennia rumphiana leaves, primarily due to the low polarity of ethyl acetate $(\mathrm{PI}=4.4)$.

\subsubsection{ABTS radical scavenging assay.}

ABTS radical cation decolorization assay is applicable to both lipophilic and hydrophilic antioxidants for screening of antioxidant activity, including flavonoids, hydroxycinnamates, carotenoids, and plasma antioxidants. The preformed radical monocation of 2, 2-azinobis- (3-ethylbenzothiazoline-6-alfonic acid) (ABTS) is generated by oxidation of ABTS with potassium persulfate and thus reduce the content of such hydrogen-donating antioxidants [34].

The IC50 values for free radical scavenging activity were between $31.90 \pm 2.61 \mu \mathrm{g} / \mathrm{ml}$ and $53.92 \pm 2.45 \mu \mathrm{g} / \mathrm{ml}$. At $100 \mu \mathrm{g} / \mathrm{ml}$ concentration, Avicennia officinalis extracts showed remarkable high ABTS radical scavenging activity (above 80\%) (Fig.2). Amongst the six solvents, ethyl acetate extract achieved the lowest IC 50 values, $31.90 \mu \mathrm{g} / \mathrm{ml}$, which is associated with the potent scavenging capacity against the free radical $\mathrm{ABTS}^{+}$. This antioxidant effectiveness of ethyl acetate extract of Avicennia officinalis was higher than that of Phoenix paludosa - a mangrove plant with $\mathrm{IC}_{50}$ values $177.6 \mu \mathrm{g} / \mathrm{ml}$. Differ from our result, the methanol extract from Mangrove Plant- Phoenix paludosa Roxb showed the highest antioxidant activity $\left(\mathrm{ABTS}^{+}, \mathrm{IC}_{50}=27.91 \mu \mathrm{g} / \mathrm{ml}\right)$ [50]. Briefly, the results in this study demonstrate that high- 
polarity solvents (e.g., ethanol and methanol) were less effective for extracting antioxidants with efficient free radical scavenging properties as compared to intermediate-polarity solvents (e.g., acetone, ethyl acetate).

\section{Conclusions}

In this study, six kinds of solvents (methanol, ethanol, ethyl acetate, acetone, dichloromethane, and chloroform) extracts from leaves Avicennia officinalis (Ca Mau province, Vietnam) were used to examine the effects of extraction solvent on total phenol, flavonoid content, and antioxidant activity of the extracts. We found that the extraction yield increased with increasing the polarity of solvents. The TPC, TFC values, and antioxidant activity (studied by DPPH and ABTS assay) were high for intermediate-polarity-solvent extract (i.e., acetone). Therefore, acetone is considered a good solvent for extracting polyphenols in Avicennia officinalis besides commonly used solvents such as methanol and ethanol. Further studies are needed to clarify the bioactive compounds individually and understand the mechanism of action for the substances fully.

\section{Funding}

This research received no external funding

\section{Acknowledgments}

The authors would like to express their hearty gratitude to Can Tho University of Medicine and Pharmacy. We also thank all of our colleagues for their excellent assistance.

\section{Conflicts of Interest}

The authors declare no conflict of interest.

\section{References}

1. Dahibhate, N.L.; Kumar, D.; Kumar K. Determination of Bioactive Polyphenols in Mangrove Species and Their in-Vitro anti- Candida Activities by Ultra-High-Performance Liquid Chromatography - Electrospray Ionization - Tandem Mass Spectrometry ( UPLC-ESI-MS / MS ). Anal. Lett. 2020, 54, 608-624, https://doi.org/10.1080/00032719.2020.1774600.

2. Bibi, S.N.; Gokhan, Z.; Rajesh, J.; Mahomoodally, M.F. Fungal endophytes associated with mangroves Chemistry and biopharmaceutical potential. South African J. Bot. 2020, 134, 187-212, https://doi.org/10.1016/j.sajb.2019.12.016.

3. Siddhuraju, P.; Becker, K. Antioxidant properties of various extracts of total phenolic constituents from three different agroclimatic origins of drumstick tree (Moringa oleifera lam) leaves. J Agric. Food Chem. 2003, 51, 2144-2155, https://doi.org/10.1021/jf020444+.

4. Kchaou, W.; Abbes, F.; Blecker, C.; Attia, H.; Besbes, S. Effects of extraction solvents on phenolic contents and antioxidant activities of Tunisian date varieties (Phoenix dactylifera L.). Ind crop prod. 2013, 45, 262269, https://doi.org/10.1016/j.indcrop.2012.12.028.

5. Stalikas, C.D. Extraction, separation, and detection methods for phenolic acids and flavonoids. J Sep Sci. 2007, 30, 3268-3295, https://doi.org/10.1002/jssc.200700261.

6. Akter, A.; Biella, P; Batary, P.; Klecka, J. Changing pollinator communities along a disturbance gradient in the Sundarbans mangrove forest: A case study on Acanthus ilicifolius and Avicennia of ficinalis. Global Ecology and Conservation 2020, 24, e01282, https://doi.org/10.1016/j.gecco.2020.e01282.

7. Pasaribu, G.; Budianto, E.; Cahyana, A.H. Toxicity and Total Phenolic Content of Saurauia vulcani Extracts from Cultivation. IOP Conf. Series: Materials Science and Engineering 2021, 1011, 012068, https://doi.org/10.1088/1757-899X/1011/1/012068. 
8. Turkmen, N.; Sari, F.; Velioglu, Y.S. Effects of extraction solvents on concentration and antioxidant activity of black and black mate tea polyphenols determined by ferrous tartrate and Folin-Ciocalteu methods. Food Chem. 2006, 99, 835-841, https://doi.org/10.1016/j.foodchem.2005.08.034.

9. Satyavani, K.; Gurudeeban, S.; Manigandan, V.; Rajamanickam, E.; Ramanathan, T. Chemical compositions of medicinal mangrove species Acanthus ilicifolius, Excoecaria agallocha, Rhizophora apiculata and Rhizophora mucronata. Current Research in Chemistry 2015, 1-8, https://doi.org/10.3923/crc.2015.1.8.

10. Rasquinha, D.N.; Mishra, D.R. Impact of wood harvesting on mangrove forest structure, composition and biomass dynamics in India. Estuar. Coast. Shelf Sci. 2021, 248, 106974, https://doi.org/10.1016/j.ecss.2020.106974.

11. Song, H.; Wang, Y.-S.; Sun, C.-C; Wang, Y.-T.; Peng, Y.-L.; Cheng, H. Effects of pyrene on antioxidant systems and lipid peroxidation level in mangrove plants, Bruguiera gymnorrhiza. Ecotoxicology. 2012, 21, 1625-1632, https://doi.org/10.1007/s10646-012-0945-9.

12. Mehta, B.; Nagar, B.; Patel, B.; Chaklashiya, P.; Shah, M.; Verma, P.; Shah, M.B. A review on a lesser known Indian mangrove: Avicennia officinalis L. (Family: Acanthaceae). Int. J. Green Pharm. 2021, 15, 1-10, http://dx.doi.org/10.22377/ijgp.v15i1.3010.

13. Roy, M.; Dutta, T.K. Evaluation of Phytochemicals and Bioactive Properties in Mangrove Associate Suaeda monoica Forssk. ex J.F.Gmel. of Indian Sundarbans. Front. Pharmacol. 2021, 12, 1-30, https://doi.org/10.3389/fphar.2021.584019.

14. Shamsuddin, A.A.; Najiah, M.; Suvik, A.; Azariyah, M.N.; Kamaruzzaman, B.Y.; Effendy, A.W.;John, B.A. Antibacterial Properties of Selected Mangrove Plants Against Vibrio Species and its Cytotoxicity Against Artemia salina. World Appl. Sci. J. 2013, 25, 333-340.

15. Mahmud, S.; Paul, G.K.; Afroze, M.; Islam, S.; Gupt, S.B.R.; Razu, M.H.; Biswas, S.; Zaman, S.; Uddin, M.S.; Khan, M.; Cacciola, N.A.; Emran, T.B.; Saleh, M.A.; Capasso, R.; Simal-Gandara, J. Efficacy of Phytochemicals Derived from Avicennia officinalis for the Management of COVID-19: A Combined in Silico and Biochemical Study. Molecules 2021, 26, 2210, https://doi.org/10.3390/molecules26082210.

16. Keshvadi, M.; Karimi, F.; Valizadeh, S.; Valizadeh, A. Comparative study of antibacterial inhibitory effect of silver nanoparticles and garlic oil nanoemulsion with their combination. Biointerface Research in Applied Chemistry 2019, 9, 4560-4566, https://doi.org/10.33263/briac96.560566.

17. Yassien, E.E.; Hamed, M.M.; Abdelmohsen, U.R.; Hassan, H.M.; Gazwi, H.S.S. In vitro antioxidant, antibacterial, and antihyperlipidemic potential of ethanolic Avicennia marina leaves extract supported by metabolic profiling. Environ. Sci. Pollut. Res. 2021, 28, 27207-27217, https://doi.org/10.1007/s11356-02112496-7.

18. Okla, M.K.; Alatar, A.A.; Al-amri, S.S.; Soufan, W.H.; Ahmad, A.; Abdel-maksoud, M.A. Antibacterial and Antifungal Activity of the Extracts of Different Parts of Avicennia marina (Forssk.) Vierh. Plants 2021, 10, 252, https://doi.org/10.3390/plants10020252.

19. Roby, M.H.H.; Sarhan, M.A.; Selim, K.A.H.; Khalel, K.I. Evaluation of antioxidant activity, total phenols and phenolic compounds in thyme (Thymus vulgaris L.), sage (Salvia officinalis L.), and marjoram (Origanum majorana L.) extracts. Industrial Crops and Products 2013, 43, 827-831, https://doi.org/10.1016/j.indcrop.2012.08.029.

20. Sopalun, K.; Laosripaiboon, W.; Wachirachaikarn, A.; Iamtham, S. Biological potential and chemical composition of bioactive compounds from endophytic fungi associated with thai mangrove plants. South African Journal of Botany 2021, 141, 66-76, https://doi.org/10.1016/j.sajb.2021.04.031.

21. Saha, S.; Bhattacharyya, S.; Sikdar (nee Bhakta), M.; Bhattachryya, R. Bioactive Compounds of Mangroves as Potent Drug and in Nanoparticle Synthesis: Play a Pivotal Role in Combating Human Pathogens. Springer, Singapore, 2021, 177-194, https://doi.org/10.1007/978-981-15-8127-4_9.

22. Assaw, S.; Mohd Amir, M.I.H.; Khaw, T.T.; Bakar, K.; Radzi, S.A.M.; Mazlan, N.W. Antibacterial and antioxidant activity of naphthofuranquinones from the twigs of tropical mangrove Avicennia officinalis. Natural Product Research 2020, 34, 2403-2406, https://doi.org/10.1080/14786419.2018.1538220.

23. Thirunavukkarasu, P.; Ramanathan, T.; Ramkumar, L.; Shanmugapriya, R.; Renugadevi, G. The antioxidant and free radical scavenging effect of Avicennia offcinalis. J Med Plants Res. 2011, 5, 4754-4758.

24. Das, S.K.; Samantaray, D.; Sahoo, S.K.; Patra, J.K.; Samanta, L.; Thatoi, H. Bioactivity guided isolation and structural characterization of the antidiabetic and antioxidant compound from bark extract of Avicennia officinalis L. S Afr J Bot. 2019, 125, 109-115, https://doi.org/10.1016/j.sajb.2019.07.011.

25. Bakshi, M.; Chaudhuri, P. Antimicrobial potential of leaf extracts of ten mangrove species from Indian Sundarban. Int J Pharm Biol Sci. 2014, 5, 294-304. 
26. Thirunavukkarasu, P.; Ramanathan, T.; Ramkumar, L.; Shanmugapriya, R. Antiulcer effect of Avicennia offcinalis leaves in Albino rats. World Applied Science Journal 2010, 9, 55-58.

27. Khushi, S.; Hasan, M.M.; Monjur-Al-Hossain, A.S.M.; Hossain, M.L.; Sadhu, S.K. Medicinal Activity of Avicennia officinalis: Evaluation of Phytochemical and Pharmacological Properties. Saudi J. Med. Pharm. Sci. 2016, 2(9), 250-255.

28. Luna, S.L.RD.; Ramırez-Garza, R.E.; Saldıvar, S.O.S. Environmentally Friendly Methods for Flavonoid Extraction from Plant Material: Impact of Their Operating Conditions on Yield and Antioxidant Properties, 2020, 2020, 6792069, https://doi.org/10.1155/2020/6792069.

29. McDonald, S.; Prenzler, P.D.; Antolovich, M.; Robards, K. Phenolic content and antioxidant activity of olive extracts. Food Chem. 2001, 73, 73-84, https://doi.org/10.1016/S0308-8146(00)00288-0.

30. Chang, C.C.; Yang, M.H.; Wen, H.M.; Chern, J.-C. Estimation of total flavonoid content in propolis by two complementary colorimetric methods. J Food Drug Anal. 2002, 10, 178-182, https://doi.org/10.38212/22246614.2748.

31. Ursini, F.; Maiorino, M.; Morazzoni, P.; Roveri, A.; Pifferi, G. A novel antioxidant flavonoid (IdB 1031) affecting molecular mechanisms of cellular activation. Free Radic Biol Med. 1994, 16, 547-553, https://doi.org/10.1016/0891-5849(94)90054-x.

32. Osman, M.A.; Mahmoud, G.I.; Shoman, S.S. Correlation Between Total Phenols Content, Antioxidant Power and Cytotoxicity. Biointerface Research in Applied Chemistry 2021, 11, 10640-10653, https://doi.org/10.33263/BRIAC113.1064010653.

33. Long, L.H.; Halliwell, B. Oxidation and generation of hydrogen peroxide by thiol compounds in commonly used cell culture media. Biochem Biophys Res Commun. 2001, 286, 991-994, https://doi.org/10.1006/bbrc.2001.5514.

34. Karthika, K.; Paulsamy, S.; Jamuna, S. Evaluation of in vitro antioxidant potential of methanolic leaf and stem extracts of Solena amplexicaulis (Arm) Gandhi. J chem Pharmaceu Res. 2012, 4, 3254-3258.

35. Sura, S.; Ali, S.; Nagar, M. Antiulcer effect of ethnolic leaf extract of Avicennia officinalis. Pharmacologyonline. 2011, 3, 12-19.

36. Sulmartiwi, L.; Pujiastuti, D.Y.; Tjahjaningsih, W.; Jariyah. Potential of mangrove Avicennia rumphiana extract as an antioxidant agent using multilevel extraction. IOP Conf. Ser.: Earth Environ. Sci. 2018. 137, 012075, https://doi.org/10.1088/1755-1315/137/1/012075.

37. Zielinski, H.; Kozłowska, H. Antioxidant activity and total phenolics in selected cereal grains and their different morphological fractions. J Agric Food Chem. 2000; 48, 2008-16, https://doi.org/10.1021/jf990619o.

38. Janmanchi, H.; Raju, A.;Degani, M.S.; Ray, M.K.; et al. Antituberculosis, antibacterial and antioxidant activities of Aegiceras corniculatum, a mangrove plant and effect of various extraction processes on its phytoconstituents and bioactivity. S. Afr. J. Bot. 2017. 113, 421-427, https://doi.org/10.1016/j.sajb.2017.09.019

39. Sultana, B.; Anwar, F.; Ashraf, M. Effect of extraction solvent/technique on the antioxidant activity of selected medicinal plant extracts. Molecules. 2009, 14, 2167-80, https://doi.org/10.3390/molecules14062167.

40. Iloki-Assanga S.B.; Lewis-Luján L.M.; Lara-Espinoza C.L.; Gil-Salido A.A.; Fernandez-Angulo D.; RubioPino J.L.; Haines D.D. Solvent effects on phytochemical constituent profiles and antioxidant activities, using four different extraction formulations for analysis of Bucida buceras L. and Phoradendron californicum. BMC Res Notes 2015, 8, 1-14, https://doi.org/10.1186/s13104-015-1388-1.

41. Rafat, A.; Philip, K.; Muniandy, S. Antioxidant potential and content of phenolic compounds in ethanolic extracts of selected parts of Andrographis paniculata. J Med plants res. 2010, 4, 197-202.

42. Febriani, A.K.; Ismiyarto, I.; Anam, K. Total Phenolic and Coumarin Content, Antioxidant Activity of Leaves, Fruits, and Stem Barks of Grey Mangrove (Avicennia marina). Journal Kimia Sains dan Aplikasi. 2020, 23, 34-38, https://doi.org/10.14710/jksa.23.2.34-38.

43. Jayaprakasha, G.; Signh, R.; Sakariah, K. Antioxidant activity of grape seed (Vitis vinifera) extracts on peroxidation models in vitro. Food Chem. 2001,73, 285-290,https://doi.org/10.1016/S0308-8146(00)00298-3.

44. Sulaiman, S.; Sajak, A.; Ooi, K.; Supriatno; Seow, E. Effect of solvents in extracting polyphenols and antioxidants of selected raw vegetables. Food companal. 2011, 24, 506-515, https://doi.org/10.1016/j.jfca.2011.01.020.

45. Ghasemzadeh, A.; Jaafar, H.; Rahmat, A. Effects of solvent type on phenolics and flavonoids content and antioxidant activities in two varieties of young ginger (Zingiber officinale Roscoe) extracts. J Med Plants Res. 2011, 5, 1147-54.

46. Das, S.K.; Samantaray, D.; Thatoi, H. Evaluation of In Vitro Antidiabetic and Antioxidant Activities and 
Preliminary Phytochemical Screening of Leaf Extracts of Avicennia officinalis. J Bioanal. Biomed. 2017, 9, 173-176, https://doi.org/10.4172/1948-593X.1000174.

47. Shah, S.S.; Shah, D.; Khan, I.; Ahmad, S.; Ali, U.; Rahman, A.U. Synthesis and Antioxidant Activities of Schiff Bases and Their Complexes: An Updated Review. Biointerface Research in Applied Chemistry 2020, 10, 6936-6963, https://doi.org/10.33263/BRIAC106.69366963.

48. Khalil, A.M.A.; Abdelaziz, A.M.; Khaleil, M.M.; Hashem, A.H. Fungal endophytes from leaves of Avicennia marina growing in semi-arid environment as a promising source for bioactive compounds. Lett. Appl. Microbiol. 2021, 72, 263-274, https://doi.org/10.1111/lam.13414.

49. Masoko, P.; Eloff J.N. Screening of twenty-four South African Combretum and six Terminalia species (Combretaceae) for antioxidant activities. Afr J Tradit Complement Altern Med. 2007, 4, 231-239, https://doi.org/10.4314/ajtcam.v4i2.31213.

50. Samarakoon, S.R.; Shanmuganathan, C.; Ediriweera, M.K.; Tennekoon, Kamani H.; Piyathilaka, Poorna.; Thabrew, Ira.; Dilip de Silva, E. In vitro Cytotoxic and Antioxidant Activity of Leaf Extracts of Mangrove Plant, Phoenix paludosa Roxb. Trop. J. Pharm. Res. 2016. 15, 127-132, https://doi.org/10.4314/tjpr.v15i1.18. 